\title{
IMIA: The Global Informatics Perspective for Good Health
}

\author{
Reinhold Haux (President of IMIA 2007-2010) \\ Peter L. Reichertz Institute for Medical Informatics, University of Braunschweig - Institute of Technology \\ and Hannover Medical School, Germany
}

\section{Introduction}

Objective: To report on IMIA, the International Medical Informatics Association, and on what has been achieved in the period 2007 2010.

Method: Summarizing IMIA's activities, discussions and decisions, in particular with respect to its Board and General Assembly meetings; looking at recent progress of biomedical and health informatics through IMIA's Yearbook.

Results: Over the last three years, decisions have been made and steps have been initiated which will lead to significant changes for IMIA. In addition to its continuing activities in being involved (1) in organizing conferences, with Medinfo 2010 as this year's highlight, (2) in publication, and (3) in working/special interest group activities, new steps were (4) extending IMIA's conference portfolio, leading to a biennial Medinfo cycle from 2015 on, (5) launching the journal Applied Clinical Informatics as a bridge from informatics theory to applications, (6) endorsing and publishing White Papers, such as the revised IMIA recommendations on education, (7) strengthening ties with WHO, and (8) establishing the Middle East Association of Health Informatics (MEAHI) as an IMIA region in order to start formalising regional organization and health and biomedical informatics activities in the Middle East. Last, but not least, IMIA's internal organization is being adapted in order to better meet future demands.

Conclusions: Finding the right balance between continuity and transition, in order to appropriately support, stimulate, and, to some extent, enable high-qualitytranslational communication, research, education, and practice in biomedical and health informatics continues to be a key challenge of IMIA.

\section{Keywords}

Medical informatics, health informatics, biomedical informatics, IMIA

Yearb Med Inform 2010: 1-5
This is my final report as President of IMIA, the International Medical Informatics Association [1]. After having served for three years, my term will end at Medinfo 2010 in Cape Town, when this Yearbook of Medical Informatics will appear.

At the end of such a three year term, it is appropriate, in this report, to look back at what has happened and, in particular, what been achieved during the years 2007 to 2010. Further to this, let me briefly introduce IMIA, and point to some important aspects of the IMIA Yearbook, and last, but not least, to IMIA's conferences such as Medinfo 2010.

\section{About IMIA, the International Medical Informatics Association}

As indicated on IMIA's web site [1], the Association's goals and objectives include:

- the promotion of informatics in health care and biomedical research,

- the advancement of international cooperation,

- the stimulation of research, development and education, and

- the dissemination and exchange of information.

As also mentioned in my report last year, for more than 40 years IMIA has been a bridging organization, as medical informatics is an integrative discipline, stimulating and enabling interdisciplinary work [2]. IMIA supports, stimulates, and, to some extent enables, high-quality translational communication, research, education, and practice in biomedical and health informatics. Inherent in IMIA's mission is the bringing together, from a global perspective, of scientists, researchers, educators, vendors, consultants and suppliers in an environment of cooperation and sharing.

From an initial founding set of twelve national groups, IMIA has grown to a worldwide network of Member Societies, IMIA Regions, Corporate and Academic Institutional Members, Working and Special Interest Groups, and affiliated organizations. Table 1 presents the growth of IMIA membership over the past five years.

At the end of 2009, 55 member societies, 52 academic institutions, and 12 corporations were directly represented as members of IMIA's growing family. Depending on the decisions of IMIA's General Assembly 2010 meeting in Cape Town, IMIA will probably continue to grow further (estimates in Table 1). In addition, there are three affiliated organizations, including the World Health Organization (WHO, [3]), where IMIA has been privileged for many years to be one of WHO's non-governmental organizations (NGO). When one includes the members of IMIA's working groups, representative member organizations exceed 150. IMIA's member societies, in turn, represent over 50,000 individuals. Further information can be found on IMIA's web site [1] and in IMIA's Yearbooks [4]. IMIA's regions, broadly aligned with WHO's regions, and consisting of IMIA member societies, actively participate in IMIA by sending a Vice President to represent their interests at the IMIA 
Board and General Assembly. IMIA regions are APAMI, the Asia Pacific Association for Medical Informatics [5], EFMI, the European Federation for Medical Informatics [6], HELINA, the African Region [1], IMIA-LAC, the Latin American and Caribbean Federation for Health Informatics [7], and the North American Region. In 2009 MEAHI, the Middle East Association for Health Informatics, [1] has become an official IMIA region; IMIA's regions now cover all parts of our world. Further information on IMIA's regions can also be found on IMIA's web site and in IMIA's Yearbooks.

\section{Looking at the Develop- ment of Our Field Through the IMIA Yearbook}

What has changed in biomedical and health informatics during recent years? What progress has been made? In order to gain an overview on the progress of our field, a look at (or even better, a careful study of) this and the recent IMIA Yearbooks of Medical Informatics, [4] is an excellent way and is highly recommended.

Starting in 1992, under the leadership of Jan H. van Bemmel and Alexa McCray, and now edited by Antoine Geissbuhler and Casimir Kulikowski, IMIA has been and continues to be, proud to have such a comprehensive yearly periodical, not only documenting but also stimulating progress in our field.

The IMIA Yearbook's traditional best paper selection, together with invited survey and review papers, may be regarded as 'THE' global observatory for progress in health and biomedical informatics.

\section{Medinfo 2010 ... and beyond}

A Medinfo conference is the premier international meeting for the medical informatics community. It brings together world leaders in our field to share knowledge and experiences.

Medinfo 2010 [8] is a unique opportunity to meet these leaders and to hear of, and contribute to, advances in biomedical and health informatics. Medinfo 2010 is IMIA's 13th world congress on medical informatics and the first one to take place in Africa. The conference theme selected for Medinfo 2010 is a topic that most countries are currently addressing: "partnerships for effective eHealth solutions - innovative collaborations promote solutions to health challenges'. The Medinfo 2010 conference proceedings [9], containing important results in research and education, and also for the practise of health care, will help to share and disseminate the outcomes of this world congress.

Medinfo 2010 has been organised and coordinated by the South African Health Informatics Association
(SAHIA). Many people have worked hard, and worked together well, to make Medinfo 2010 a great success. Let me here in particular acknowledge the chairpersons of the Organising Committee, Lyn Hanmer (South Africa); of the Scientific Program Committee, Riccardo Bellazzi (Italy) and Johanna Westbrook (Australia); and of the Editorial Committee, Charles Safran (USA).

Within the period 2007 to 2010, a number of other conferences have taken place in which IMIA has been involved. Let me here mention just a few of the major regional or global events, particularly because they were where IMIA's General Assemblies, Board meetings, or other significant IMIA related meetings took place. Among these conferences were MIE 2008 (Gothenburg, Sweden), InfoLAC 2008 (Buenos Aires, Argentina), Helina 2009 (Grand Bassam, Ivory Coast), Nursing Informatics 2009 (Helsinki, Finland), and the Collaborative Meetings in Health Informatics 2009 (CoMHI 2009, Hiroshima, Japan). Details of many of these can be found in my reports in the previous Yearbooks. Besides the traditionally well-established international conferences in the regions Asia-Pacific, Europe and North America, it was impressive to see the progress in Africa and in Latin America. My sincere congratulations to all those concerned!

After the Medinfo 2010 congress in Cape Town, the 14th world congress on medical informatics will take place in

Table 1 IMIA members. The numbers are calculated at the end of the calendar year. Estimates for 2010.

\begin{tabular}{|l|c|c|c|c|c|}
\hline IMIA Members & 2010 & 2009 & 2008 & 2007 & 2006 \\
\hline Member Societies & 56 & 52 & 53 & 52 & 46 \\
Academic Institutions & 52 & 51 & 49 & 48 & 43 \\
Corporations & 12 & 12 & 11 & 12 & 10 \\
Corresponding Members (Countries) & 34 & 35 & 33 & 33 & 31 \\
Total & 154 & 151 & 146 & 145 & 130 \\
\hline
\end{tabular}


2013 in Copenhagen, Denmark, as decided by vote of the IMIA General Assembly 2009 in Hiroshima, Japan. Although it is still three years in the future, IMIA is already now looking forward to, and planning for, a successful Medinfo 2013.

\section{What Has Been Achieved?}

What has been achieved during the years 2007 to 2010, with respect to IMIA?

First of all, let me mention the continuing activities of IMIA in organizing or contributing to international meetings, this year with the Medinfo 2010 conference as its major highlight.

Second, the relevance of IMIA in publishing high-quality outcomes on research, education and practice in our field can hardly be underestimated. The IMIA Yearbook as 'flagship' had already been mentioned, but this periodical may be regarded as the tip of the iceberg with respect to IMIA publications (e.g. [10]).

Third, let me emphasize the continuous and important work of IMIA's working and special interest groups in their specific areas, through working conferences, publications and other activities.

Besides these continuing activities, important new activities have been initiated and decisions have been made ... - ... on IMIA's conference portfolio.

As our field is becoming more important, there was a need to re-examine the sequence of international conferences. The need to inform about and to discuss recent progress in our field had obviously increased within recent years. Together with our regional medical informatics organizations, a joint portfolio of international conferences has been worked out, where high-level, peerreviewed results of health and biomedical informatics research and practice can be presented and discussed, independent of financial or political interests. One major step in this context is that from 2015 onwards, Medinfo conferences will take place every two years, i.e. that we move from a triennial sequence to a biennial sequence of Medinfo conferences. With this step, changes in how we organize Medinfos will also be considered.

- ... on IMIA's publication portfolio. IMIA has for several years already had several prestigious publications, including, for example, the IMIA Yearbook and the Medinfo conference proceedings. It also has two renowned official journals, the International Journal of Medical Informatics and Methods of Information in Medicine. Both are research-oriented journals. An international peer-reviewed journal, designed to cultivate broad readership across health care, in order to communicate on informatics topics of translational interest and on the application of informatics principals was, however, missing. It had previously been suggested [11] that such an applied informatics journal might appeal to practicing physicians, healthcare administrators and CIOs, as well as health / medical informaticians, and that in a globalized world, with eHealth initiatives spanning across borders, such a journal should be an international effort. For these reasons, IMIA initiated and helped to launch, in 2009, the electronic journal Applied Clinical Informatics (ACI, [12]). It became an official journal of IMIA for applications, in order to stimulate and support bridging theory and practice in our field. My acknowledgements go to Schattauer Publishing Company for deciding to take the financial risk in launching this new journal, and to Christof Lehmann for his tireless work as editor of ACI. I am glad to say that evidence points to ACI's launch having been very successful, and that the journal has been well received.

- ... on IMIA's 'White Papers'. Succeeding the approval of IMIA's Strategic Plan 'Towards IMIA 2015' with its associated documents, a project led by Nancy Lorenzi and Peter Murray [14, 15], in 2009, IMIA endorsed its revised recommendations on education (chaired by John Mantas, [16]), and in 2008 the "statement on reporting of evaluation studies in health informatics" (chaired by Jan Talmon, [17]). Judging by the impressively high number of downloads since their publication, it is expected that the revised education recommendations will again be widely used. The recommendations on education now also consider aspects of program accreditation by IMIA, which has been often requested, and which may have organizational consequences for IMIA.

- ... on strengthening ties with WHO. As announced in a communiqué in 2007 ([18]), WHO and IMIA reaffirmed their wish to further their collaboration. This collaboration is, in my opinion, now well-established (see e.g. [19]). With having Antoine Geissbuhler as IMIA liaison officer to WHO, new links are being established, and with Najeeb Al-Shorbaji from WHO as a distinguished keynote speaker at Medinfo 2010, this closer collaboration is becoming more visible.

- ... on establishing MEAHI. After years of preparatory work, the IMIA General Assembly decided in 2009 to establish the Middle East Association of Health Informatics (MEAHI), in order to start forming a regional organization in the Middle East. There is still a considerable way to go for MEAHI to become sufficiently mature as a regional organization, but now having a formal umbrella in this upcoming part of the world may help to strengthen biomedical and health informatics research, education and applications with the support of IMIA. With the continuous support of Hiroshi Takeda from IMIA's Board, and with Ramin Moghaddam as MEAHI's first President, major steps have been made in the past and will need to be continued in the fu- 
ture. With MEAHI, IMIA regions now cover all parts of our world.

- ... on IMIA's office and organization. Additional tasks have been added to IMIA as an organization. Publication activities have been increased during recent years, e.g., through the IMIA Yearbook of Medical Informatics. With having Medinfo conferences every two years from 2015 onwards, IMIA will need to explore its provision of conference services, which go beyond the support given to Medinfo today, through collaboration with our local organizers. Working and Special Interest Groups could also benefit from such extension of conference and related services. Global projects related to health and biomedical informatics are coming up more frequently, and as a result of requests to be involved, IMIA will explore how best to be involved in such projects, and to contribute actively in its role as an NGO of WHO. With the new IMIA recommendations on education the demand for accreditation of educational programs will be raised, and will need to be addressed. To meet these demands, an IMIA office with permanent address has been inaugurated in 2009. With the decision to establish such an office and with the excellent appointment of Peter Murray as IMIA's new Executive Director in this year, succeeding Steven Huesing [20], this office can now be extended in a stepwise manner.

In 2010, the IMIA Award of Excellence was given jointly to Marion Ball and Hans Peterson, an important highlight which will be celebrated during Medinfo 2010. A number of excellent persons were proposed to the nomination committee, and the committee finally and unanimously decided to make the award to these two outstanding colleagues. My sincere congratulations go to them. It is my hope that we will be able to read a written version of their award lecture at Medinfo 2010 in the next IMIA Yearbook. Their article should also be as excellent and worth read, complementing those of their predecessors, François Grémy as the first recipient of the award in 2004 in San Francisco [21], and Jan van Bemmel as the second recipient of the award in 2007 in Brisbane [22].

Last, but not least, a more internal, but nevertheless necessary and important activity should be mentioned. The IMIA Statutes have to be revised and updated. Depending on the outcome of the 2010 IMIA General Assembly, this revision might have been approved, at least in parts, or even completely, allowing IMIA to be more flexible in its activities and better prepared for future developments.

\section{Publications on IMIA}

During my term as IMIA President, a number of articles have been published by me as (co-) author with respect to IMIA [18, 20, 23-32]. The motivation for all these publications has been to inform about and promote IMIA, and to stimulate discussions or activities.

In addition to the annual 'President's Statements' in the IMIA Yearbook ([23, 24] and this one) let me point to four additional 'thematic papers', published in 2007 [29], 2008 [30], 2009 [31], and 2010 [32], each of them addressing specific topics, related to IMIA. The last one on the past, present and future of medical informatics [32] can be regarded as a final 'gift' from me in my time as IMIA President.

\section{Final Remarks}

In the beginning of my presidency I mentioned, that IMIA should continue to pursue, and even magnify, its endeavors to achieve the following aims [29]:

1 That IMIA should be the leading international organization in health and biomedical informatics by stimulating and communicating high quality research, education and applications in a new and one world, with medical informatics becoming one of the central disciplines for achieving health for people of all societies, through our field's contributions to high-quality, efficient health care and to high-quality research in biomedicine and in the health and computer sciences.

2 That this be done jointly with IMIA's constituent member societies and its regional and institutional members through conferences and meetings, through publications and awards, through its working groups, special interest groups and other committees, and through supporting excellent students and excellent young researchers in our field, regardless of where in the world they come from, by striving to achieve the aims defined in IMIA's Strategic Plan.

3 That IMIA with its members becomes an advisor and partner of national and international bodies devoted to health, health care, and health and biomedical informatics research, such as WHO.

4 That IMIA's secretariat and organization be prepared to contribute intensely and successfully to manage these new sets of opportunities and responsibilities.

5 Finally, that IMIA provides an example for the successful, tolerant and peaceful collaboration among individuals, across and beyond our nations and cultures, for the sake of good health and quality of life achievable for the people of our world.

An assessment of the extent to which some of these aims have been adequately achieved during the last three years, and the extent to which there is still some way to go, can and should not be done by myself, but I leave to others to judge. Important tasks in IMIA's future have been mentioned in [32], section 4.4 , to which I want to refer here. Again, I finally would like to remind you that IMIA, an umbrella association of associations, societies, institutions and corporations, in reality consists of individuals that represent those mem- 
bers. If not already involved, you are cordially invited to join in IMIA's global efforts. Please be aware that the role of IMIA for the informatics community worldwide on the one side and, even more important, for high quality, efficient health care and for progress in research on the other side can hardly be underestimated.

\section{Acknowledgements}

As IMIA President, I had the duty and the privilege to work with the members of the IMIA family in leading our association through this important time of growth and maturation. As during recent years, many people have contributed so much to IMIA so that it is hardly possible for me to mention them all. My respect and my acknowledgements are conveyed to all of them. I am particularly grateful to the IMIA Board and to the IMIA Regional leadership, who (individually and collectively) have been unstinting in their support and cooperation in these challenging times. They have once again demonstrated their personal excellence and commitment to IMIA. My best wishes for the future are with the incoming IMIA President, Antoine Geissbuhler, and with Peter Murray as IMIA's Executive Director, for leading this prestigious and important association during the next years.

\section{References}

1. http://www.IMIA.org. Last access June 19, 2010. 2. van Bemmel JH. Medical informatics is interdisci- plinary avant la lettre. Methods Inf Med 2008;47:318-21.

3. http://www.WHO.int. Last access June 19, 2010.

4. http://www.imiapubs.org and http://www. schattauer.de/de/magazine/uebersicht/zeitschriften-az/imia-yearbook/. Last access: June 19, 2010.

5. http://www.APAMI.org. Last access June 19, 2010.

6. http://www.EFMI.org. Last access June 19, 2010.

7. http://www.IMIA-LAC.net. Last access June 19, 2010.

8. http://www.medinfo2010.org. Lastaccess June 19, 2010.

9. Safran C, Marin H, Reti S, editors. Medinfo 2010. Amsterdam: IOS Press; 2010 (in print).

10, Peterson HE, Hutter M. IMIA's publication history. Yearb Med Inform 2007:192-6.

11. Ball MJ, Silva JS, Bierstock S, Douglas JV, Norcio $\mathrm{AF}$, Chakraborty J, et al. Failure to provide clinicians useful IT systems: opportunities to leapfrog current technologies. Methods Inf Med 2008;47:4-7.

12. http://www.aci-journal.org. Last access June 19, 2010.

13. Mantas J, Ammenwerth E, Demiris G, Hasman A, Haux R, Hersh W, et al. IMIA Recommendations on Education Task Force. Recommendations of the International Medical Informatics Association (IMIA) on education in biomedical and health informatics. First revision. Methods Inf Med 2010;49:105-120.

14. Lorenzi NM. Towards IMIA 2015 - the IMIA strategic plan. Yearb Med Inform 2007:1-5.

15. Murray PJ. The IMIA strategic plan-towards IMIA 2015. Yearb Med Inform 2008:7-15.

16. Recommendations of the International Medical Informatics Association (IMIA) on education in health and medical informatics. Methods Inf Med 2000;39:267-77.

17. Talmon J, Ammenwerth E, Brender J, de Keizer N, Nykänen P, Rigby M. STARE-HI -statement on reporting of evaluation studies in health informatics. Int J Med Inform. 2009;78:1-9. Reprint in Yearb Med Inform 2009:23-31.

18. Geissbuhler A, Haux R, Kwankam SY. Towards health for all: WHO and IMIA intensify collaboration. Joint Communiqué during Medinfo 2007 in Brisbane. Methods Inf Med 2007; 46: 503-5.

19. Kay M, Santos J. Report on the World Health Organization Global Observatory for eHealth strategic planning workshop, April 2008. Methods Inf Med 2008;47:381-7.

20. Haux R, Lorenzi NM, Lun KC, Rienhoff O, van Bemmel JH. In memoriam Steven A. Huesing (1944-2009). Yearb Med Inform 2009:7-12.

21. Grémy F. Hardware, software, peopleware, subjectivity. A philosophical promenade. Methods Inf Med 2005;44:352-8.
22 van Bemmel JH. Reflections on curiosity. Yearb Med Inform 2008:183-8.

23. Haux R. Health care and informatics: on IMIA's opportunities and responsibilities in its 5th decade. Yearb Med Inform 2008:1-6.

24. Haux R. IMIA and its Members: on balancing continuity and transition in biomedical and health informatics. Yearb Med Inform 2009:1-6.

25. Haux R, Murray PJ. On IMIA's international activities in health and biomedical informatics education. Methods Inf Med 2010;49:305-9.

26. Geissbuhler A, Haux R, Kulikowski CA. From ambient assisted living to global information management: IMIA-Referencing Publications in 2008. Yearb Med Inform 2009:143-5.

27. Murray P, Haux R, Lorenzi N. Let a thousand flowers bloom: transition towards implementation of the IMIA strategic plan. Methods Inf Med 2007;46:625-8.

28. Murray P, Haux R, Lorenzi N. eHealth and IMIA's Strategic Planning Process. Stud Health Technol Inform 2008;134:15-20.

29. Haux R. Preparing for change: medical informatics international initiatives for health care and biomedical research. Comput Methods Programs Biomed 2007;88:191-6.

30. Haux R, Howe J, Marschollek M, Plischke M, Wolf KH. Health-enabling technologies for pervasive health care: on services and ICT architecture paradigms. Inform Health Soc Care 2008;33:77-89.

31. Haux R, Ball MJ. From theory into practice: bridging the clinical informatics divide! Appl Clin Inf 2009;0:8-11.

32. Haux R. Medical informatics: past, present, future. Int J Med Inform 2010 (to appear).

Correspondence to:

Dr. Reinhold Haux

President, International Medical Informatics Association

IMIA's Head Office:

81 Boulevard de la Cluse, 1205 Geneva, Switzerland

Tel: +41(0)22/3727 249

Skype: imia-office

E-mail: imia@imia-services.org, www.IMIA.org

Professor and Director

Peter L. Reichertz Institute for Medical Informatics

University of Braunschweig - Institute of Technology

and Hannover Medical School

Muehlenpfordtstr. 23, 38106 Braunschweig, Germany

Tel: +49(0)531/3919501

E-mail: Reinhold.Haux@plri.de, www.plri.de 